\title{
Potential factors of specialists' willingness to write editorial and commentary: a retrospective study based on 5,091 invitations
}

\author{
Hengrui Liang ${ }^{1 \#}$, Lujiao Ye ${ }^{2 \#}$, Wenhua Liang ${ }^{1 \#}$, Runchen Wang ${ }^{3}$, Fan Ge ${ }^{4}$, Lihua Fan ${ }^{2}$, Yao Zhu ${ }^{2}$, \\ Grace S. Li ${ }^{2}$, Stephen D. Wang ${ }^{2}$, Kevin Phan ${ }^{5}$, Alan Sihoe ${ }^{6}$, Kaiping Zhang ${ }^{2}$, Jianxing $\mathrm{He}^{1}$ \\ ${ }^{1}$ Department of Thoracic Surgery and Oncology, the First Affiliated Hospital of Guangzhou Medical University, State Key Laboratory of Respiratory \\ Disease, National Clinical Research Center for Respiratory Disease, Guangzhou Institute of Respiratory Health, Guangzhou 510000, China; ${ }^{2}$ AME \\ Publishing Company, Guangzhou 510000, China; ${ }^{3}$ Nanshan School, ${ }^{4}$ The First Clinical College, Guangzhou Medical University, Guangzhou 510000, \\ China; ${ }^{5}$ Collaborative Research (CORE) Group, Macquarie University, Sydney, Australia; ${ }^{6}$ Gleneagles Hong Kong Hospital, Hong Kong, China \\ Contributions: Conception and design: H Liang, L Ye, K Zhang; (II) Administrative support: J He, K Zhang, SD Wang; (III) Provision of study \\ materials or patients: L Ye, K Zhang, R Wang, L Fan, Y Zhu; (IV) Collection and assembly of data: L Ye, R Wang, K Zhang, L Fan, Y Zhu; (V) Data \\ analysis and interpretation: H Liang, K Zhang; (VI) Manuscript writing: All authors; (VII) Final approval of manuscript: All authors. \\ "These authors contributed equally to this work. \\ Correspondence to: Jianxing He. Department of Thoracic Surgery and Oncology, the First Affiliated Hospital of Guangzhou Medical University, \\ State Key Laboratory of Respiratory Disease, National Clinical Research Center for Respiratory Disease, Guangzhou Institute of Respiratory \\ Health, Guangzhou 510000, China. Email: drjianxing.he@gmail.com; Kaiping Zhang. AME Publishing Company, Guangzhou 510000, China. \\ Email: zhangkp@amegroups.com.
}

Background: Editorials and commentaries (E/C) are common article categories and usually solicited by editors in many journals. However, not all experts accept invitation for an E/C essay for a variety of reasons. We conducted this study to explore the potential influence factors contributing whether an invitation to write E/C is accepted by a specialist.

Methods: Data of invited E/C from all journals of AME Publishing Company between January $1^{\text {st }}, 2018$ and December $31^{\text {st }}, 2018$ were retrospectively identified and consecutively collected. Acceptance of writing E/C from experts was recorded as "positive", while acceptance without submission, refusal, or no response, were all recorded as "negative". Factors that could potentially affect invitation acceptance were generally categorized as being related to three areas: original studies, inviting journals, and experts.

Results: A total of 5,091 invitations were sent to 4,788 experts from 79 different countries or areas to write $\mathrm{E} / \mathrm{C}$ on 695 research papers from 43 journals, with a total positive acceptance rate of $18.88 \%$. Greece (40.54\%), India (36.8\%), and Brazil (35.42\%) were the top three countries for acceptance rate. Surgeons (surgeons $23.80 \%$ vs. non-surgeons $17.05 \%$; $\mathrm{P}<0.001$ ) and oncologists (oncologists $22.57 \%$ vs. nononcologists $17.58 \% ; \mathrm{P}=0.029)$ were more likely to accept the $\mathrm{E} / \mathrm{C}$ invitations. The acceptance rate decreased with the increasing number of published articles of an expert $(\mathrm{P}=0.005)$. The acceptance rate was the highest $(28.03 \%)$ when an inviting journal was indexed in both SCIE and PubMed. ABS, VATS and $7 T D$ ranked as the top three journals with the highest invitation acceptance rate. The impact factor of journals on which original papers were published had a negative correlation with the invitation acceptance rate $(\mathrm{P}=0.015)$. Database-related studies had the highest acceptance rate (21.66\%), while translational (16.49\%) and basic studies $(16.56 \%)$ had a significantly lower acceptance rate among all study types.

Conclusion: Original studies, inviting journals, and expert-related factors were all influence factors on the acceptance rate/willingness to write of $\mathrm{E} / \mathrm{C}$ from invitations.

Keywords: Editorials; commentary; AME Publishing Company; academic communication

Submitted Oct 12, 2019. Accepted for publication Dec 04, 2019.

doi: $10.21037 / \mathrm{atm} .2019 .12 .75$

View this article at: http://dx.doi.org/10.21037/atm.2019.12.75 


\section{Introduction}

Editorials and commentaries (E/C) are usually written by editors or experts invited by journal editors. In most medical journals' protocols, an editorial is written by a recognized leader(s) in a specific field, usually on an original article of the inviting journal. Similarly, commentary articles discuss original papers, reports, inside or outside of the inviting journal or events of the whole scientific area, published within the past few months or so, or in the near future. E/ C serve many purposes; they can provide commentary on original articles, concisely review academic topics, and offer perspectives on recent developments that are deemed by the editor to be important to readers of the journal and the community (1). The majority of medical journals solicit editorials (2), with some journals, like Thoracic Surgery Clinics and Anesthesiology Clinics, focusing exclusively on invitations for editorial papers.

AME (academic made easy, excellent and enthusiastic) Publishing Company is a globally active open access publisher specializing in the publication of medical journals and books across the broad spectrum of science, technology and medicine, with more than 60 open access peer-reviewed journals (13 indexed in SCIE and 18 indexed in PubMed) covering various fields of medicine including oncology, pulmonology, cardiothoracic disease, andrology, urology, etc. For years, several AME journals have published invited $\mathrm{E} / \mathrm{C}$ on topics of interest (3-15). These informative E/C have provided readers concise and insightful information.

Many creative and prolific experts across different fields around the world have participated in this project. However, not all experts accept AME's invitation for an E/ $\mathrm{C}$ opportunity. Some state that they are too busy, others say they are not experts on the invited topic, still others never reply to the invitation email. We are obviously not alone in receiving these reactions when sending invitations (16).

In order to explore the potential influence factors of whether an invited author contributes to $\mathrm{E} / \mathrm{C}$ writing and to provide a guidance for editors, we accessed the E/C invitation data of AME Publishing Company and conducted this study.

\section{Methods}

Data of invited E/C from all journals of AME Publishing Company between January $1^{\text {st }}, 2018$ and December $31^{\text {st }}$, 2018 were identified and consecutively collected through electronic invitation records. The editorial office will decide together with section editors and academic editors whom to invite to write an E/C. Three situations will occur after sending these invitation letters: acceptance, refusal, or no response from experts. Even after acceptance, a great many experts will fail to submit the E/C. In this study, only a successful submission was analyzed as "positive" (acceptance group), while acceptance without submission, refusal, and no response were all analyzed as "negative" (failure group).

Factors that could potentially affect invitation acceptance were categorized into three parts: (I) original studyrelated factors including impact factor of the journal in which commented articles were published, study type of the commented article, disease type, journal name, the duration between invitation time and publishing time of the commented article (ahead of print); (II) inviting journalrelated factors including indexing in SCIE, indexing in PubMed, journal name, annual volume, and founding time; and (III) expert-related factors including occupation, nationality, and numbers of publications indexed in PubMed at the time of invitation. All factors were compared in the acceptance group and failure group.

Categorical variables are given as a count and percentage and were compared using the $\chi^{2}$ or Fisher's exact test. Logistic regression was used to test the correlation between the acceptance rate and variables. All statistical tests were two-sided. $\mathrm{P}$ values of less than 0.05 were considered significant. SPSS software (SPSS version 25.0; IBM Corp, Armonk, NY, USA), R (3.6.1) and GraphPad Prism 6.0 software were used for all data analysis.

\section{Results}

\section{An overview of editorial and commentary invitation}

Between January $1^{\text {st }}, 2018$ and December $31^{\text {st }}$, 2018, AME editors sent a total of 5,140 invitations. After excluding ineligible invitations, 5,091 were sent to 4,788 experts from 79 different countries or areas to write $\mathrm{E} / \mathrm{C}$ on 695 research papers from 43 journals. The process of collecting these E/C papers from AME Publishing Company is shown in Figure 1. The New England Fournal of Medicine (NE7M: 29 papers), Fournal of Clinical Oncology (FCO: 26 papers), and Surgical Endoscopy (25 papers) were the top three popular journals where about $11.5 \%$ of the 695 research papers were published. The USA (1,980 experts), Japan (476 experts), and Italy (383 experts) are ranked as the top three countries in invited expert number; the nationality distribution of countries with over ten invited experts is shown in 


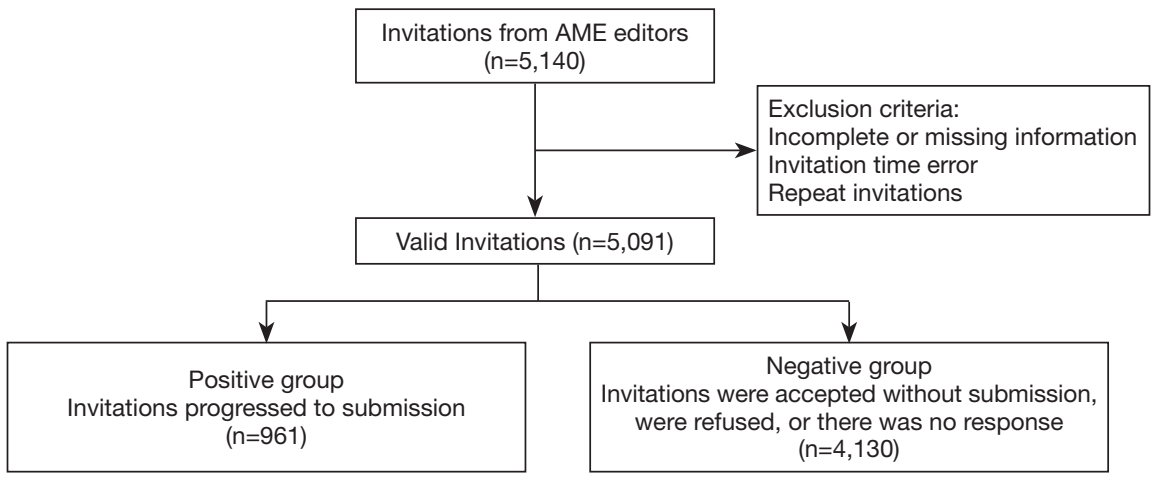

Figure 1 Flow chart of invitation screening.
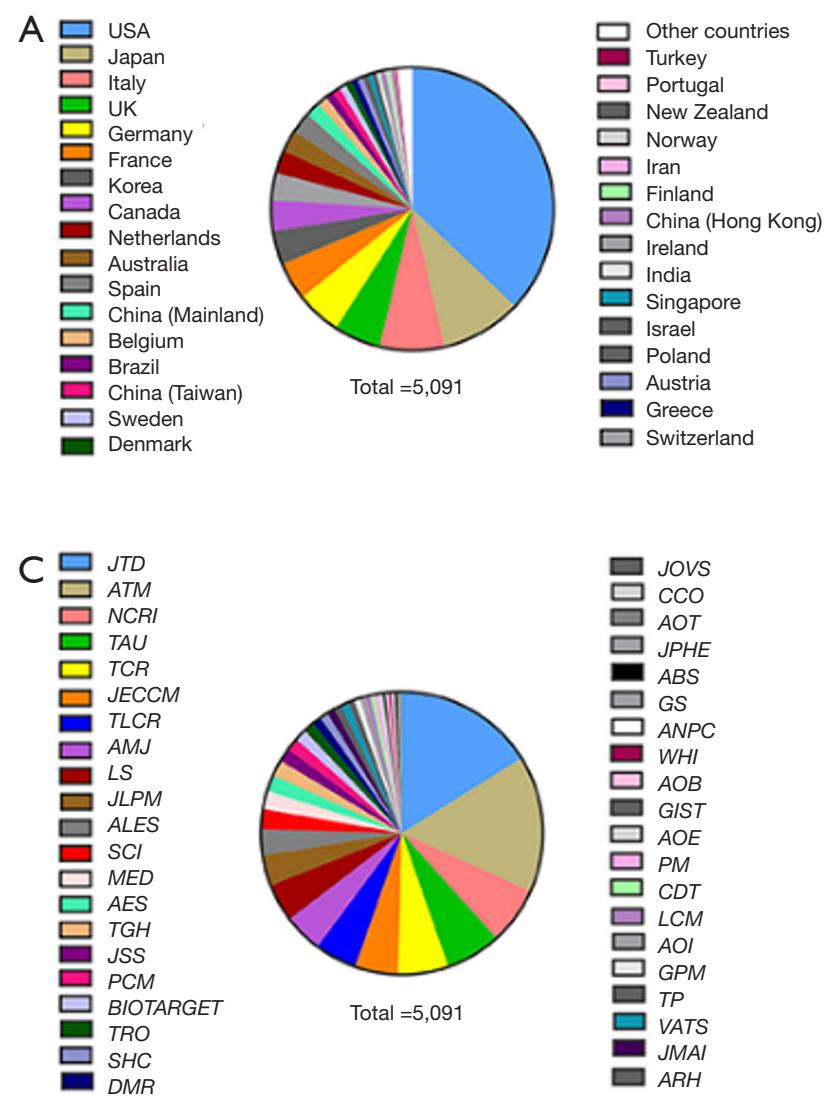

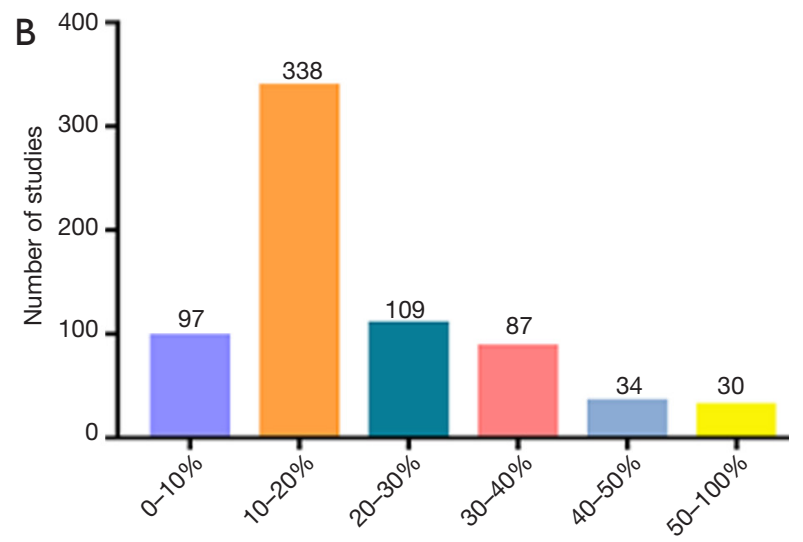

Acceptance rate of editorial invitation

Figure 2 An overview of editorial and commentary invitation and acceptance. (A) The nationality distribution of invited international experts; (B) the acceptance rate distribution of $\mathrm{E} / \mathrm{C}$ invitations on research studies; (C) the distribution of invited $\mathrm{E} / \mathrm{C}$ published in $\mathrm{AME}$ journals. $\mathrm{E} / \mathrm{C}$, editorials and commentaries.

Figure 2A, with countries of 10 or less invited experts being shown as "other countries".

Among 5,091 invitations, 961 invitations resulted in submitted $\mathrm{E} / \mathrm{C}$, and 4,130 invitations were accepted without submission, refused, or were not responded to, with a total positive acceptance rate of $18.88 \%$. The distribution of acceptance rate is shown in Figure 2B. For each specific research paper, E/C acceptance rate was also calculated 


\section{Page 4 of 9}

as a ratio of numbers of acceptance and numbers of total invitations; $9.35 \%$ research papers had acceptance rates of less than $10 \%, 4.32 \%$ research papers had acceptance rates over $50 \%$, and only $2.73 \%$ of research papers had an $100 \%$ acceptance rate. The most popular research paper selected by AME editors is a database study on paraneoplastic syndromes and thymic malignancies (17) and a total of 36 experts were invited by editors, among whom 6 accepted the invitation.

A total of 41 journals of AME Publishing Company were involved in the medical $\mathrm{E} / \mathrm{C}$ invitation program, 4 of which are indexed by SCIE, and 10 of which are indexed by PubMed. Fournal of Thoracic Disease (7TD: 820), Annals of Translational Medicine (ATM: 794), and Non-coding RNA Investigation (NCRI: 336) ranked as the top three journals in total invited expert number (Figure 2C).

\section{Influence factors of acceptance rates (experts)}

Experts from 18 countries or areas contributed E/C for AME journals with a total acceptance rate of $18.88 \%$. Greece (40.54\%), India (36.80\%), and Brazil (35.42\%) had the top three highest acceptance rates (Figure $3 A$ ). We invited 16 and 12 experts from Finland or Iran for E/C, respectively; however, none of their experts accepted our E/C invitation. In addition, surgeons were more likely to accept the E/C invitations than other experts (surgeons $23.80 \%$ vs. nonsurgeons $17.05 \% ; \mathrm{P}<0.001$ ), and oncologists were also associated with a higher acceptance rate than non-oncologists (oncologists 22.57\% vs. non-oncologist $17.58 \%$; $\mathrm{P}=0.029$ ).

When selecting experts for E/C, AME editors usually search the relevant key words in a discipline and the name of the expert in PubMed, finding the experts' interest area and deciding whether to send an invitation. The number of publications in PubMed of each invited expert ranged from 0 to 1,496 . The average number of publications in the acceptance group was significantly lower than that of the failure group (93 vs. 105; $\mathrm{P}=0.004$ ) (Figure 3B). We divided all the experts into four groups according to the quartile of their published article number: 0-38, 39-69, 70-130, and over 130. The acceptance rates of the four groups are shown in Figure 3C. According to logistic regression, we found the acceptance rate of the experts to be significantly decreased with an increase in the number of the published articles $(\mathrm{P}=0.005)$.

The AME section editors sent invitations once to 4,540 experts (twice for 204 experts, three times for 34 experts, four times for 8 experts, and five times for

\section{Liang et al. Editorials and commentaries: what's behind the story}

2 experts). Among these authors, 41 accepted our request after one invitation (twice for 34 experts, three times for 5 experts, and four times for 2 experts). The number of positive acceptance times for each number of invitations group is shown in Figure 3D. With an increased number of invitations for one expert, the positive acceptance times were also increased.

\section{Influence factors of acceptance rate (inviting journals)}

Every E/C invitation was sent in the name of a journal in AME. Introduction of the inviting journal would be shown in the email, which was also an important factor for acceptance rate. Annals of Breast Surgery (ABS: 30.00\%), Video-Assisted Thoracic Surgery (VATS: 29.55\%) and Fournal of Thoracic Disease (FTD: 29.39\%) ranked as the top three journals with the highest invitation acceptance rate. However, for the top ten (acceptance rate) journals in this ranking (Figure $4 A$ ), only $7 T D$ sent over 300 invitations (820 in total), of which 241 experts accepted.

Whether an inviting journal is indexed by SCIE or PubMed is an important consideration factor for authors (Figure $4 B$ ). We found the E/C acceptance rate was the highest $(28.03 \%)$ when an inviting journal was indexed both in SCIE and PubMed. However, if the inviting journal was not indexed by either SCIE or PubMed, the E/C acceptance rate was the lowest (15.60\%). The first group (SCI/PubMed) had a significantly higher acceptance rate than the last group (non-SCI/non-PubMed) $(\mathrm{P}<0.001)$.

\section{Influence factors of acceptance rate (original papers)}

Whether the original papers are of enough interest to experts is one of the most essential elements in the whole process of E/C invitation, and it is worthwhile exploring which type of original paper is the most popular to experts. According to the logistic regression, the impact factor of original papers had a negative correlation with the invitation acceptance rate $(\mathrm{P}=0.015)$ (Figure $5 A)$. The period between $\mathrm{E} / \mathrm{C}$ invitation and the time for ahead of print of inviting article was not associated with the acceptance rate $(\mathrm{P}=0.586)$ (Figure 5B).

The average E/C acceptance for articles from NEFM, Lancet, and $7 A M A$ were $18.97 \%, 12.36 \%$, and $9.32 \%$, respectively. Meanwhile, average $\mathrm{E} / \mathrm{C}$ acceptance for articles from Cell, Nature and Science were 13.89\%. Interestingly, E/ $\mathrm{C}$ acceptance for articles from the top three thoracic surgery journals (The Fournal of Thoracic and Cardiovascular Surgery, 


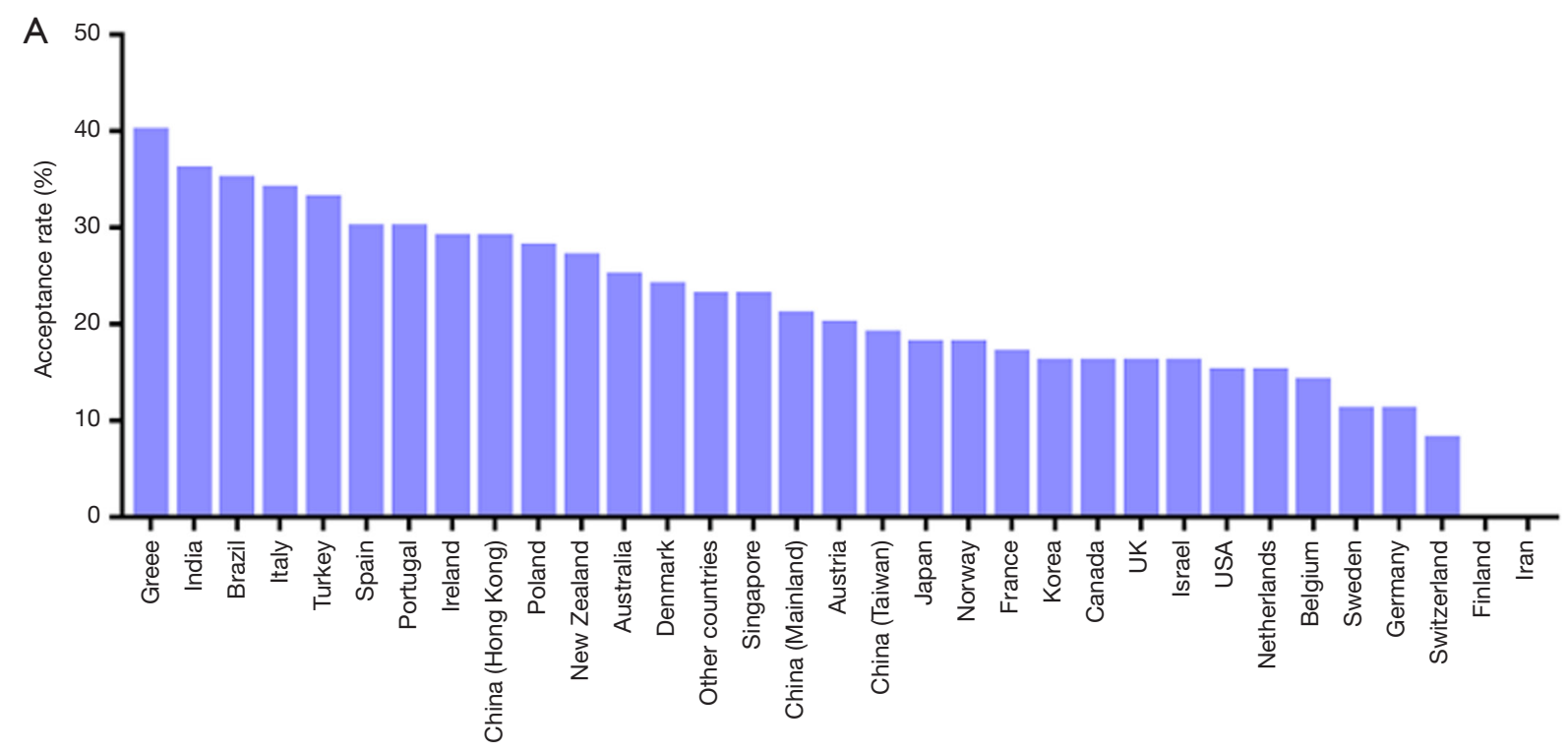

B

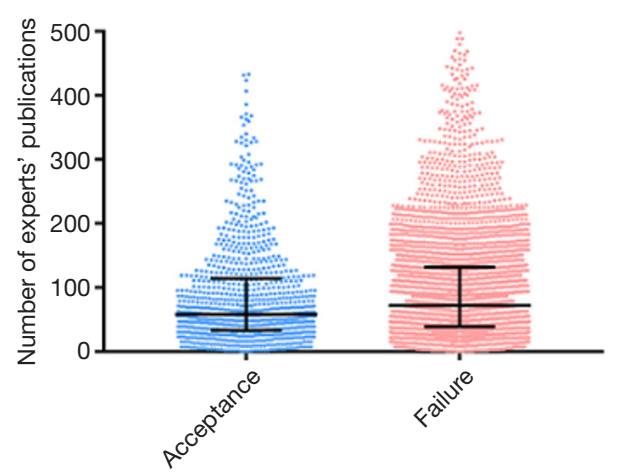

D

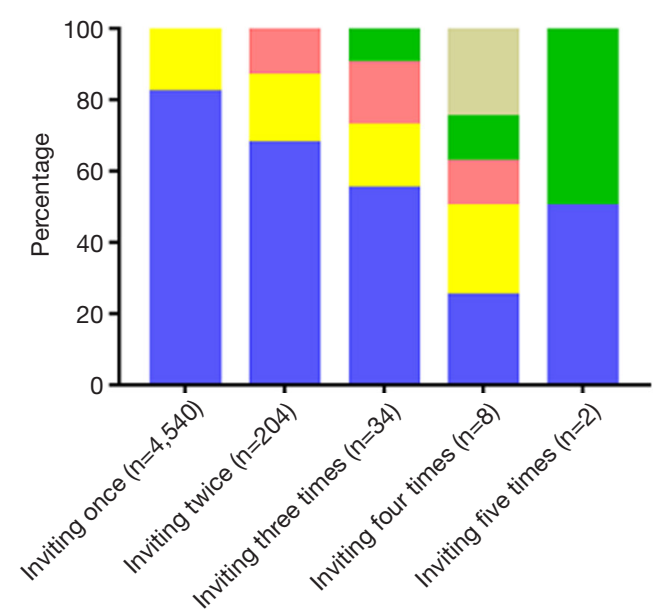

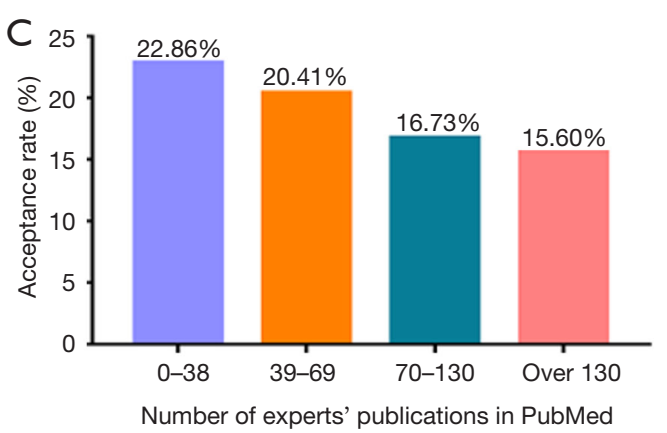

Positive four times

Positive three times

Positive twice

Positive once

Negative

Figure 3 Influence factors of acceptance rate (experts). (A) Acceptance rate of E/C by countries or areas; (B) the distribution of experts' publications in the acceptance and failure group; (C) the acceptance rate of experts according to their number of published articles; (D) the acceptance rate distribution according to the number of invitations. E/C, editorials and commentaries. 

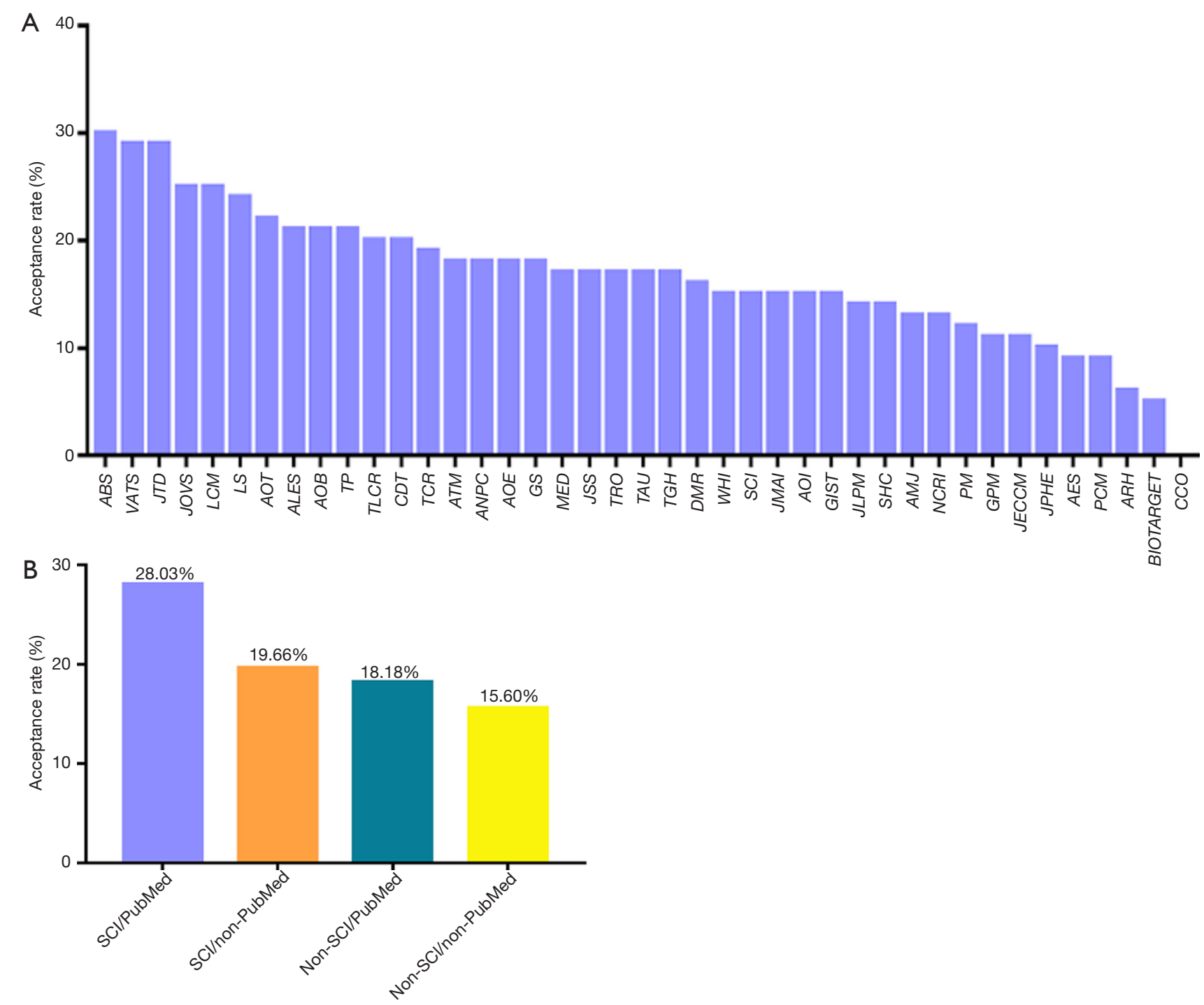

Types of inviting journal of AME

Figure 4 Influence factors of acceptance rate (inviting journals). (A) Acceptance rate of invited E/C in different journals of AME; (B) acceptance rate of $\mathrm{E} / \mathrm{C}$ in journals of $\mathrm{AME}$ with different index situations. $\mathrm{E} / \mathrm{C}$, editorials and commentaries.

Annals of Thoracic Surgery and European Fournal of CardioThoracic Surgery) was the highest among all disciplines, with the average acceptance rate of $29.61 \%$. Among all study types, database-related studies had the highest acceptance rate $(21.66 \%)$, while translational $(16.49 \%)$ and basic studies $(16.56 \%)$ had a significantly lower acceptance rate (Figure 5C). In line with the high acceptance rate of surgeons and oncologists, surgical (21.13\%) and oncology (20.60\%) studies had the top two highest acceptance rates among all study areas (Figure 5D).

\section{Discussion}

E/C articles are important elements of academic and scientific journals and should help to foster informative and responsible discussion of the issues related to the articles they accompany (18), It is also an effective way to enhance the reputation, quality, and impact of the journal (19). E/ $\mathrm{C}$ serve many purposes in most medical journals, including as comments on original articles published in the recent issue of the journal, concise reviews of topics on very recent developments, and concerns or historical perspectives that 

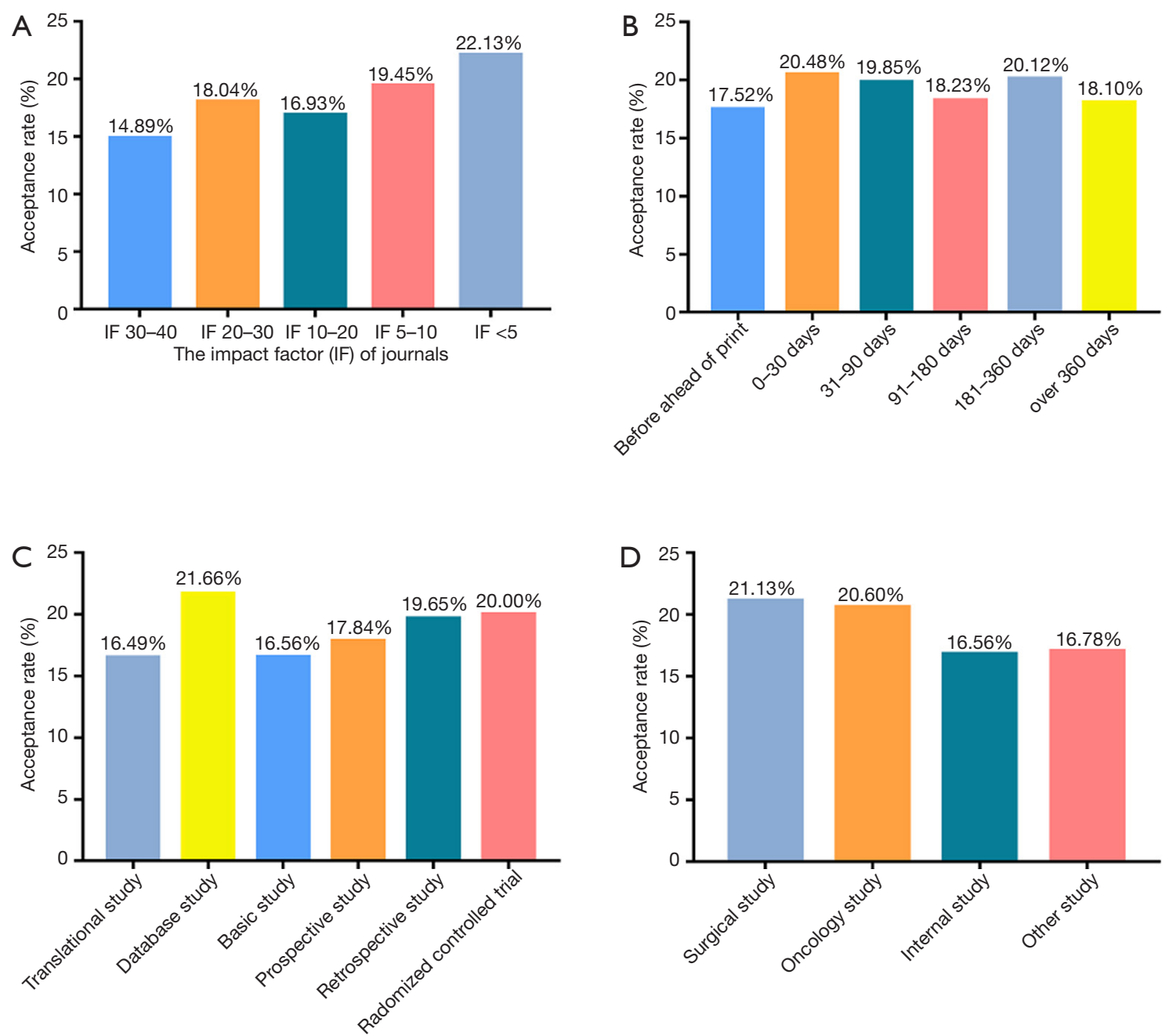

Figure 5 Influence factors of acceptance rate (original papers). (A) Acceptance rate of E/C commenting on journals with diverse impact factors; (B) acceptance rate for $\mathrm{E} / \mathrm{C}$ according to the period between $\mathrm{E} / \mathrm{C}$ invitation and the time of printing the inviting papers; (C) acceptance rate for $\mathrm{E} / \mathrm{C}$ according to study types of inviting papers; (D) acceptance rate for E/C according to study areas of inviting papers. $\mathrm{E} / \mathrm{C}$, editorials and commentaries.

are deemed by the editor to be important to readers and the community. In the past, $\mathrm{E} / \mathrm{C}$ were always written by the editor himself/herself (1). Currently, an invitation to write an $\mathrm{E} / \mathrm{C}$ is considered a high honor, and most experts would readily accept it.

This study prospectively collected data of $\mathrm{E} / \mathrm{C}$ invitations from comprehensive academic publishing company, with the aim to explore the influence factors for the acceptance rate of an $\mathrm{E} / \mathrm{C}$ invitation. We divided all variables into the three aspects we deemed as the most important factors during our daily work of inviting E/C: experts, inviting journals, and inviting original papers.
The original intention of this investigation was to provide guidance for AME editors to select appropriate experts for an E/C. Interestingly, we found several insightful preliminary findings. First, the acceptance for E/C of experts varied with different countries. Second, we observed that busier experts (experts that published more than 130 papers) had less time or will to accept an invitation for E/C writing. Third, surgeons and oncologists were more likely to accept the E/C invitations than other experts. Fourth, experts tended to accept E/C from invitations of SCIE \& PubMed indexed journals, while invitations from non-SCIE \& non-PubMed indexed journals were associated with 


\section{Page 8 of 9}

a lower acceptance rate. Fifth, database-related original studies had the highest acceptance rate. However, as they are limited by a sample size and the diversity of journal types, these results need to be interpreted with caution.

In addition to the above, inviting original research from the three top thoracic surgery journals (FTCVS, ATS and EFCTS) was more likely to result in positive reception from $\mathrm{E} / \mathrm{C}$ from experts, with invitations from $\mathcal{F} T D$ having the relatively higher acceptance rate. These finding indicate that thoracic surgeons are more likely to accept an E/C invitation, and this is may be due to the fact that $\mathcal{F T D}$ was the first journal in AME to be indexed in SCIE; thus, it is better known in the community of thoracic surgeons.

We acknowledge several limitations in the study. First, the reason for experts to refuse $\mathrm{E} / \mathrm{C}$ invitation were not collected in detailed. However, from our experience of sending invitations, the majority failure cases were no response, followed by experts saying their lack of time, and few experts indicating themselves no experts in that field. Second, many other relevant factors that could affect invitation acceptance rate were not available. For example, how familiar the expert was with this subject; how much the expert was comfortable with writing in English; how old and what gender was the expert, etc. Third, retrospective data from one single publishing company (AME) also limited the extrapolation of results. However, this study shall provide readers and editors an open visual field of editorials, commentaries and publishing.

The style of $\mathrm{E} / \mathrm{C}$ is less restricted than that of original research papers, which enables authors to express themselves more freely. E/C from AME journals have covered perspectives both on clinical and basic research. The nature of content ranges from a focus on topical issues in clinical progress to a voicing of biomedicalrelated concerns. Importantly, we would like to express our sincere gratitude to all section editors, academic editors, reviewers, authors, and other editors. It is largely thanks to them that AME's E/C project is a success. In the future, we hope to receive even more compelling and insightful contributions from authors across to world to better inform our readership in all areas of medical care.

\section{Acknowledgments}

None.

\section{Footnote}

Conflicts of Interest: This study is supported by materials from

\section{Liang et al. Editorials and commentaries: what's behind the story}

AME Publishing Company. We have received permission to use and publish these data from AME Publishing Company.

Ethical Statement: The authors are accountable for all aspects of the work in ensuring that questions related to the accuracy or integrity of any part of the work are appropriately investigated and resolved.

\section{References}

1. Peh WC, $\mathrm{Ng} \mathrm{KH}$. Writing an editorial. Singapore Med J 2010;51:612-5.

2. Hofman A. A note of thanks and an invitation. Eur J Epidemiol 2018;33:1131-3.

3. van der Does WF, de Groot NM. Prophylaxis with amiodarone for postoperative atrial fibrillation: when and who? J Thorac Dis 2018;10:S3831-3.

4. Brunel A, Samain R, Neuzillet C, et al. Identification of two cancer-associated fibroblast markers revealing stromal heterogeneity in sustaining cancer progression and chemoresistance. Transl Cancer Res 2018;7:S718-21.

5. Shigematsu Y, Inamura K. Gut microbiome: a key player in cancer immunotherapy. Hepatobiliary Surg Nutr 2018;7:479-80.

6. Langabeer SE. Incidental abnormal bone marrow signal on magnetic resonance imaging and reflexive testing for the JAK2 V617F mutation. Quant Imaging Med Surg 2018;8:881-2.

7. Cho SF, Anderson KC, Tai YT. BCMA CAR T-cell therapy arrives for multiple myeloma: a reality. Ann Transl Med 2018;6:S93.

8. Gössl M, Sorajja P. MitraClip patient selection: inclusion and exclusion criteria for optimal outcomes. Ann Cardiothorac Surg 2018;7:771-5.

9. Galetta D, Pizzutilo P, Longo V. BRMS1 expression in resected lung adenocarcinoma. Transl Lung Cancer Res 2018;7:S364-6.

10. Brodie A, McCauley N, Cresswell J, et al. T1G3 bladder cancer, bacillus Calmette-Guerin and radical cystectomy: continued debate. Transl Androl Urol 2018;7:S692-5.

11. El Lakis M, Kebebew E. Neural monitoring in endocrine neck surgery. Gland Surg 2018;7:S86-8.

12. De Maria E, Ziacchi M, Diemberger I, et al. Leadless left ventricular endocardial pacing: a real alternative or a luxury for a few? Cardiovasc Diagn Ther 2018;8:530-3.

13. Tjen-A-Looi SC, Fu LW. Sustained effects of acupuncture 
in treatment of chronic constipation. Ann Palliat Med 2017;6:S124-7.

14. Lloyd S. Pancreas cancer, careful improvements and human connections. J Gastrointest Oncol 2018;9:979-81.

15. Yokoi A. Congenital tracheal stenosis: what should we look at for successful tracheoplasty? Transl Pediatr 2018;7:229-32.

16. Please, decline our invitation-again. Hum Reprod 2018;33:1801.

Cite this article as: Liang $\mathrm{H}$, Ye L, Liang W, Wang R, Ge F, Fan L, Zhu Y, Li GS, Wang SD, Phan K, Sihoe A, Zhang K, He J. Potential factors of specialists' willingness to write editorial and commentary: a retrospective study based on 5,091 invitations. Ann Transl Med 2019;7(24):805. doi: 10.21037/atm.2019.12.75
17. Padda SK, Yao X, Antonicelli A, et al. Paraneoplastic Syndromes and Thymic Malignancies: An Examination of the International Thymic Malignancy Interest Group Retrospective Database. J Thorac Oncol 2018;13:436-46.

18. Fontanarosa PB. Editorial matters: guidelines for writing effective editorials. JAMA 2014;311:2179-80.

19. Gray R. Now hang on a minute: five rules for writing an editorial. J Psychiatr Ment Health Nurs 2015;22:559-60. 